\title{
Comparison Of Expected Yields For Light Radioactive Beams At SPIRAL-1 And 2
}

\author{
Saint-Laurent M.-G. ${ }^{\text {a }}$, Pichard A. ${ }^{\text {a }}$, Lhersonneau G. ${ }^{\text {a }}$, de Oliveira Santos \\ F. ${ }^{\mathrm{a}}$, Pellemoine F. ${ }^{\mathrm{a}}$, Delahaye P. ${ }^{\mathrm{a}}$, Fadil M. ${ }^{\mathrm{a}}$, Frånberg H. ${ }^{\mathrm{a}}$, Leroy R. ${ }^{\mathrm{a}}$, \\ Hass M. ${ }^{\mathrm{b}}$, Hirsh T. ${ }^{\mathrm{b}}$, Serani L. ${ }^{\mathrm{c}}$, Alfaurt P. ${ }^{\mathrm{c}}$, Demonchy C.-E. ${ }^{\mathrm{c}}$, Fournier \\ A. ${ }^{c}$, Stora T. ${ }^{\mathrm{d}}$, Hodak R. ${ }^{\mathrm{d}}$ and the GANISOL group ${ }^{\mathrm{a}}$ \\ ${ }^{a}$ GANIL,CEA/DSM CNRS/IN2P3, Bd H. Becquerel, B.P. 55027 F-14076 Caen Cedex, France \\ ${ }^{b}$ The Weizmann Institute of Science, Rehovot, Israel \\ ${ }^{c}$ CENBG, Université Bordeaux 1, UMR5797 CNRS/IN2P3, BP120, 33175 Gradignan Cedex, France. \\ ${ }^{d}$ ISOLDE, CERN, CH-1211, Geneva 23, Switzerland.
}

\begin{abstract}
Light-particles stable high-intensity beams (p, d, $\left.{ }^{3,4} \mathrm{He} . ..\right)$ will be available from the Linac driver accelerator of SPIRAL-2. Yields of neutron-deficient isotopes as well as of neutron-rich isotopes (by means of reactions with secondary neutrons) are compared with those presently available at the SPIRAL-1 facility. We explore, for light beams $(\mathrm{Z}<16)$ asked in the 'white book' of SPIRAL- ${ }^{1}$, the production methods taking into account the in-target yield but also the feasibility of making such beams by the ISOL method (considering reaction, target, thermal and release properties). We discuss some of the tests needed and planned. A comparison with the present and potentially attainable yields at SPIRAL-1 is presented.
\end{abstract}

Keywords: Reaccelerated radioactive beams, Sources of radioactive nuclei, Nuclear reactions PACS: 29.38.Gj, 29.25. Rm, 24

\section{INTRODUCTION}

A major goal of SPIRAL-2 ${ }^{2,3}$ is to produce neutron-rich heavy radioactive beams using natural-uranium fission. Neutrons are generated by deuteron stopping in a thick target, the so-called converter. The new superconducting LINAC accelerator, driver of SPIRAL-2, shall accelerate other light and heavy ions with high intensities. Fusionevaporation residues, transfer or deep-inelastic products, using n, p, d, ${ }^{3,4} \mathrm{He}$ and heavy-ion beams can thus be produced using a variety of targets. Two working groups have been formed for the "SPIRAL-2 Preparatory phase" 4 in the context of the $7^{\text {th }}$ Framework program (FP7): one (task 7.1) is composed of GANIL (France), Soreq Nuclear Research Center and Weizmann Institute (Israel) physicists. Its role is to study the production options for the intense light ion beams listed above. Another working group (task 7.2) is composed of CENBG-Bordeaux and IFIN-HH-Bucarest with the aim to study the production of radioactive beams induced by heavy ions.

The subject of this contribution is the comparison of yields expected for light radioactive beams at SPIRAL-1 and after an upgrade permitting new fragmentation reactions and those at SPIRAL-2. The goal of the study is to find out what is the most promising alternative in order to concentrate development efforts on it. We review 
nuclear reactions induced by p, d, ${ }^{3} \mathrm{He},{ }^{4} \mathrm{He}$ (with energies up to 33, 40, 72.5 and 80 $\mathrm{MeV}$, respectively, corresponding to the Linac maximum energy ${ }^{5}$ ) and those induced by secondary neutrons generated by a $40 \mathrm{MeV}-5 \mathrm{~mA}$ deuteron beam on a graphite thick target.

\section{STATUS OF RADIOACTIVE BEAMS AT SPIRAL-1}

\section{Available Radioactive Beams at SPIRAL-1}

The present SPIRAL-1 uses heavy-ion projectile fragmentation, a graphite target and a standard $\mathrm{N}^{+}$-ECR ion source, equipped with a cold transfer pipe between target and ion source. The radioactive beams available after acceleration are ${ }^{6,8} \mathrm{He},{ }^{13} \mathrm{~N}$, ${ }^{14,15,19-22} \mathrm{O},{ }^{18,20-21} \mathrm{~F},{ }^{17-19,23-27} \mathrm{Ne},{ }^{31-35,42-46} \mathrm{Ar}$ and ${ }^{72-77,79,81} \mathrm{Kr}{ }^{6}$. The cold transfer pipe traps non-volatile elements and therefore allows for a high degree of beam purification, transmitting only noble gases and volatile molecules stable at high temperature to the ion source. However, with such device, non-volatile beams are not possible and effusion time reduces the efficiency of volatile elements with short radioactive period.

\section{Tests with radioactive $1+$ ions}

Extensive R\&D on the extraction of non-gaseous elements as $1^{+}$ion has been carried out at GANIL using the on-line test bench SIRA separator. An ECR-1+ ion source without cold transfer pipe ${ }^{7}$ and a Surface Ionization Source ${ }^{8}$ were tested.

The nuclei ${ }^{32,33,34} \mathrm{Cl},{ }^{30,31} \mathrm{~S},{ }^{29,30} \mathrm{P},{ }^{28,29} \mathrm{Al}$ and ${ }^{21,22,23,27} \mathrm{Mg}$ have been produced using ${ }^{36} \mathrm{Ar}$ projectile fragmentation ${ }^{7}$ and ionized with the ECR. The total efficiencies (diffusion-effusion, 1+ ionization, extraction at $20 \mathrm{kV}$ and transport) were between $3 \times 10^{-2}$ and $1 \times 10^{-4}$, depending on the isotopes. Hydrides ( $\mathrm{HCl}, \mathrm{HS}, \mathrm{HP}$, due to residual vacuum) were also observed. Keeping stable intensity during a long running period has still to be demonstrated. The yields could be improved using dedicated incident beams $\left({ }^{32} \mathrm{~S},{ }^{28} \mathrm{Si}\right.$ or $\left.{ }^{24} \mathrm{Mg}\right)$ leading to greater cross-sections. During the tests, the ion source was sensitive to the $\mathrm{C}$ target out-gassing and difficult to tune.

The nuclei ${ }^{47} \mathrm{~K},{ }^{25,26,27,28} \mathrm{Na},{ }^{28,29,30,31} \mathrm{Al}$ and ${ }^{8,9} \mathrm{Li}$ have been produced using ${ }^{48} \mathrm{Ca}$ projectile fragmentation ${ }^{8}$ and $1+$ ionized by surface ionization in a carbon pipe. The total extraction efficiencies depend of the isotopes. They are from $4.3 .10^{-1}$ for ${ }^{25} \mathrm{Na}$ to 1.6. $10^{-2}$ for ${ }^{28} \mathrm{Na}$. These yields could be improved using a more suitable primary beam $\left({ }^{26} \mathrm{Mg},{ }^{30} \mathrm{Si}\right.$ or $\left.{ }^{36} \mathrm{~S}\right)$.

In general the target adaptation with a 1+ ion source (ECR with a bigger plasma volume and without transfer pipe, surface ionization source, or hot Febiad with hot transfer tube) taking into account the available space in the storage shielding remains to be done ${ }^{9}$. 


\section{Possible RIB's at SPIRAL-1}

The accelerated and 1+ beams mentioned above are first steps towards new beams at SPIRAL-1. In particular the release out of $\mathrm{C}$ target has been demonstrated for the elements $\mathrm{He}, \mathrm{Li}, \mathrm{N}, \mathrm{O}, \mathrm{F}, \mathrm{Ne}, \mathrm{Na}, \mathrm{Mg}, \mathrm{Al}, \mathrm{P}, \mathrm{S}$ and $\mathrm{Cl}$. In the case of non-volatile elements an appropriate ion source has to be used. Release has to be demonstrated for Be, C, B and Si: Beryllium beams are produced with a UC2/graphite target at ISOLDE ${ }^{10}$ and a Ta target at TRIUMF ${ }^{11}$. Radioactive carbon ions cannot be released without exchanging the C-target material. An authorization from safety authorities is needed to change the nature of the target at SPIRAL-1. Finally, the elements boron and silicon have never been, to our knowledge, extracted as radioactive isotopes by the ISOL method.

Post-acceleration with the cyclotron CIME requires a high charge state. The $1+$ ion source will be modified in the context of a new $1+/ \mathrm{N}+$ breeder at SPIRAL- $1{ }^{9}$.

\section{NEUTRON-DEFICIENT BEAMS AT SPIRAL-1 AND SPIRAL-2}

The in-target yields (particles per second) expected at SPIRAL-2 for ${ }^{14,15} \mathrm{O},{ }^{18} \mathrm{~F}$, ${ }^{18,19} \mathrm{Ne},{ }^{21,22} \mathrm{Na},{ }^{22,23} \mathrm{Mg},{ }^{26} \mathrm{Si},{ }^{29} \mathrm{P},{ }^{30,31} \mathrm{~S},{ }^{33} \mathrm{Cl}$ are reported in fig. 1 . The primary beams are $\mathrm{p}$, d, or ${ }^{3,4} \mathrm{He}$ with assumed current of $100 \mu \mathrm{Ap}$. The targets are: $\mathrm{C}, \mathrm{MgO}, \mathrm{Al}_{2} \mathrm{O}_{3}$ oxides, and the $\mathrm{SiC}$ carbide, all known for their refractory character. They are already used at ISOL installations, although at much lower deposited power. Yields shown are calculated using experimental cross-sections taken from literature (open circles) when existing or from the simulation database EAF07 ${ }^{12}$ (squares), or the code PACE4 ${ }^{13}$ (triangles). When using cross-sections the following equation (eq.1) is used

$$
\text { Yield }=I \cdot \int \frac{d x}{d E}(E) \cdot \sigma(E) \cdot d E
$$

Only reactions leading to the best yields are reported. Some $10^{10}$ to $10^{11}$ pps are expected. Exceptions are ${ }^{22} \mathrm{Mg}$ and ${ }^{33} \mathrm{Cl}$ for which no reactions using solid targets in the available energy range of primary beams were found. Yields in the SPIRAL-1 graphite target are also calculated (filled circles) using the EPAX parameterization version $2^{14}$, at $1.5 \mathrm{~kW}$. For $100 \mu \mathrm{Ap}$, a factor 10 in favor of SPIRAL-2 is observed, but it does not take into account the problem of beam power dissipation in the production target. Yet, efficiency of products release has not been considered.

\section{Production of ${ }^{14} \mathrm{O}$ at SPIRAL2}

The oxygen isotopes ${ }^{14} \mathrm{O}$ and ${ }^{15} \mathrm{O}$ have been identified as the neutron-deficient light beams to be investigated with highest priority for SPIRAL- $2^{1}$. We discuss production of ${ }^{14} \mathrm{O}$ in some detail. 


\section{Cross Sections}

The reaction which has the largest cross-section to produce ${ }^{14} \mathrm{O}$ is ${ }^{14} \mathrm{~N}(\mathrm{p}, \mathrm{n}){ }^{14} \mathrm{O}{ }^{15}$. However, it implies release of oxygen from gaseous $\mathrm{N}$ target or from a solid $\mathrm{BN}$ target. Oxygen release out of BN target has not been observed at Louvain-La-Neuve ${ }^{16}$. The ${ }^{12} \mathrm{C}\left({ }^{3} \mathrm{He}, \mathrm{n}\right){ }^{14} \mathrm{O}$ and ${ }^{12} \mathrm{C}\left({ }^{4} \mathrm{He}, \mathrm{n}\right){ }^{15} \mathrm{O}$ reactions have therefore been investigated for a first study for SPIRAL-2. A solid graphite target allows ${ }^{14,15} \mathrm{O}$ extraction via the CO molecule. Unfortunately, yields deduced from experimental cross-sections ${ }^{17}$ and those directly measured for a thick-target ${ }^{18}$ differ by a factor 7 . At SPIRAL-1 the reaction used to produce this isotope is ${ }^{16} \mathrm{O}$ projectile fragmentation on a $\mathrm{C}$ target. An in-target yield gain, 10 to 70 times depending on the actual cross-section, could be achieved at SPIRAL-2 with respect to SPIRAL-1. This estimate is calculated using realistic conditions implying the present $1.5 \mathrm{~kW}$ target for SPIRAL-1 and a $5 \mathrm{~kW}$-target (30 $\mathrm{MeV}, 0.16 \mathrm{~mA},{ }^{3} \mathrm{He}$ ) for SPIRAL-2. Because of the factor 7 of uncertainty for SPIRAL-2, the in-target ${ }^{14,15} \mathrm{O}$ cross-section will be measured at the Nuclear Physics Institute Rez (Czech Republic) ${ }^{19}$.

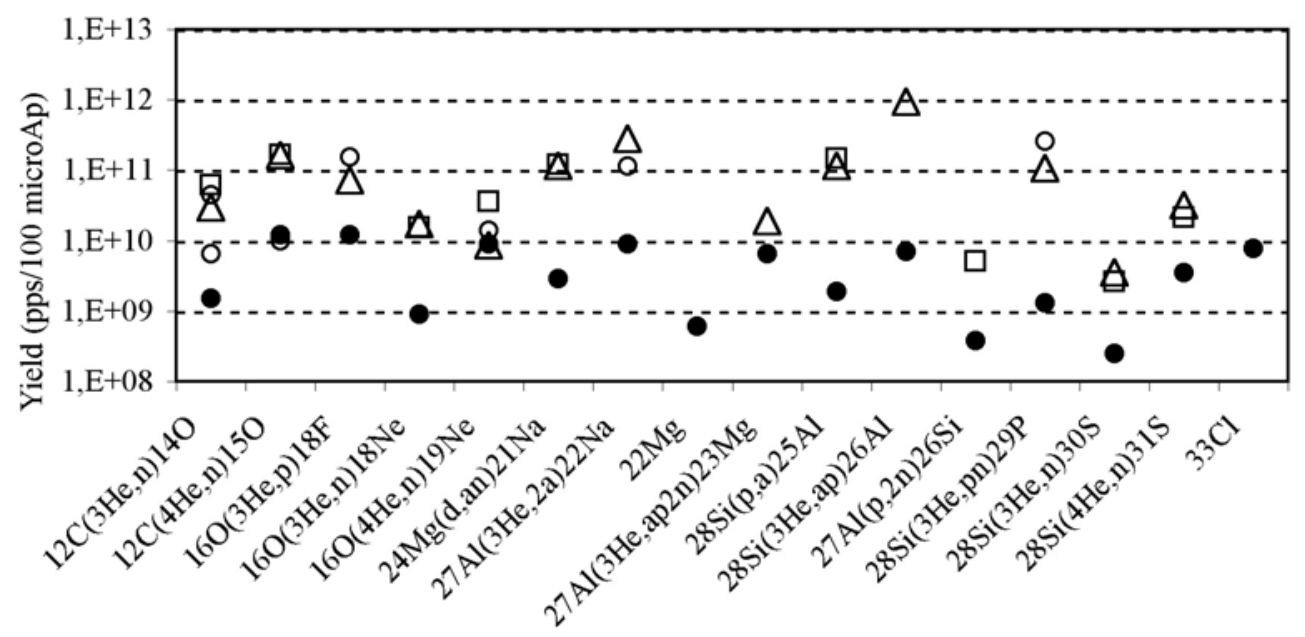

FIGURE 1 Expected yields (pps) for SPIRAL-2 using 100 microAp p, d, or ${ }^{3,4} \mathrm{He}$ calculated using cross-sections from literature (open circles) from PACE4 code (triangles) and simulation database EAF07 (squares) and yields in the SPIRAL-1 C target (filled circles).

\section{Thermal Issues}

In order to dissipate high beam power, the primary beam has to be defocused on the target, implying the use of large radius and thin target material. Thermal tests of Cfoils have been performed at AIFIRA at CENBG, Bordeaux, using their on-line pyrometers with a $1 \mathrm{MeV}$ proton beam. Figure 2 shows the foil temperature dependence on beam intensity. Diamonds, circles and squares correspond to 3 different pyrometers suitable in different temperature range. The influence of target 
thickness for the same flexible foil material is shown in fig. 2a. Two graphite types of same thickness do not exhibit large temperature differences (fig. 2b).

Thermal simulations are being performed at GANIL in order to determine how much primary $35 \mathrm{MeV}^{3} \mathrm{He}$ power can be sustained by the C-target. The ${ }^{3} \mathrm{He}$ range in C is $0.74 \mathrm{~mm}$ (for $\rho=1.8 \mathrm{~g} / \mathrm{cm}^{3}$ ). In a first approach, we have limited the target box size to the space available for the UCx container of SPIRAL-2. A schematic drawing of the C-target (fig 3) was simulated using the code Comsol Multiphysics ${ }^{20}$ in $2 \mathrm{D}$ with axial symmetry axis. The stainless-steel box was cooled by water assuming a thermal conductivity coefficient $\mathrm{k}=4.45 \mathrm{~W} \cdot \mathrm{m}^{-1} \cdot \mathrm{K}^{-1}$.Temperature was calculated as a function of the primary beam intensity (fig 4a). The graphite target for a flat beam of $4 \mathrm{~cm}$ radius can accept an intensity of $200 \mu \mathrm{Ap}$. Influence of beam shape has also been explored (fig 4b). It shows the importance of defocusing and flatness of the ${ }^{3} \mathrm{He}$ beam. The calculation predicts a temperature increase of $300 \mathrm{~K}$ at $\mathrm{I}=100 \mu \mathrm{A}(800 \mathrm{~K}$ at 500 $\mu \mathrm{A}$ ) if a Gaussian beam profile with $90 \%$ of intensity within $4 \mathrm{~cm}$ target radius is used instead of a flat one (fig $4 \mathrm{~b}$ ). These preliminary simulations will be pursued using a more realistic target box drawing.

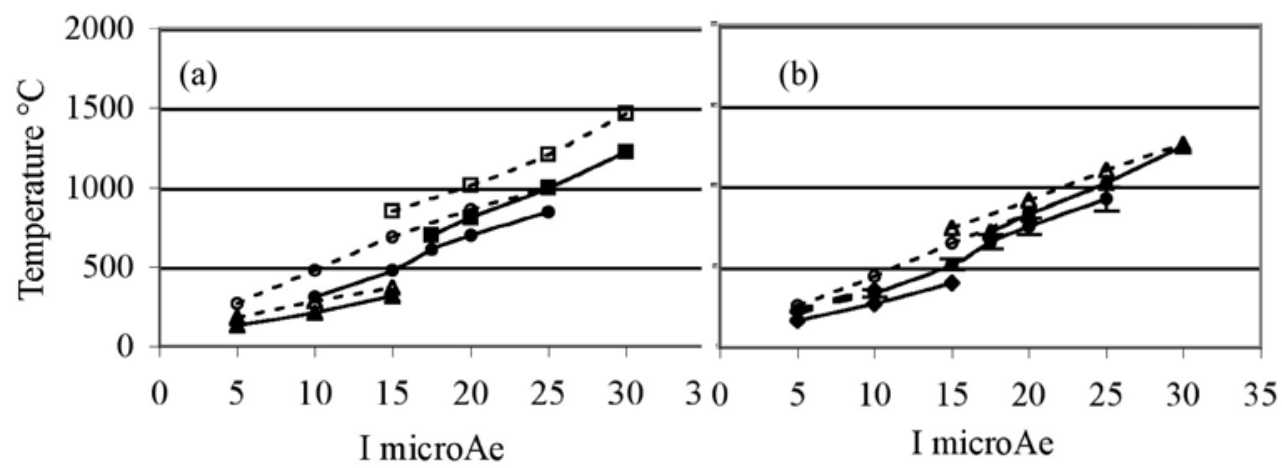

FIGURE 2 : Temperature in graphite foils versus $1 \mathrm{MeV}$ proton intensity: a) for flexible $\mathrm{C}$ foils of thickness 125 (filled symbol) and $75 \mu \mathrm{m}$ (open symbol), b) for flexible (filled symbol) and rigid (open symbol) $\mathrm{C}$ foils both of $125 \mu \mathrm{m}$ thick.

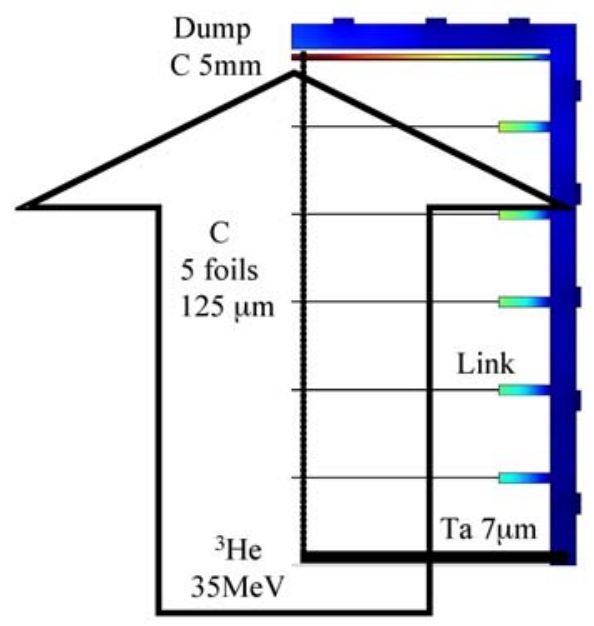

FIGURE 3 : Schematic drawing of the simulated C-target (only half of target is shown). 

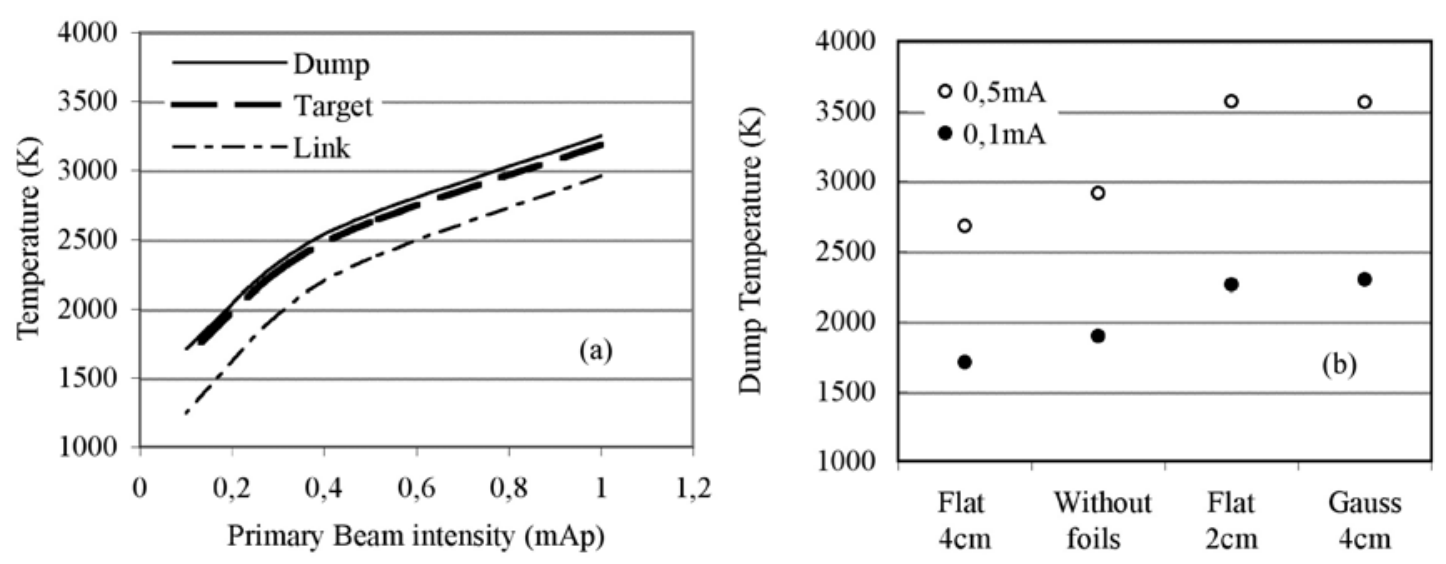

FIGURE 4 : a) Temperature as function of the primary beam intensity for a flat $35 \mathrm{MeV}-{ }^{3} \mathrm{He}$ beam of $4 \mathrm{~cm}$ radius, b) Dump temperature for different beam profiles.

\section{NEUTRON-RICH BEAMS AT SPIRAL-1 AND SPIRAL-2}

The neutron-rich nuclei ${ }^{6} \mathrm{He}$ and ${ }^{8} \mathrm{Li}$ were chosen to be investigated with highest priority for SPIRAL-2 and SARAF. We discuss also our attempts to find a production scheme for ${ }^{15} \mathrm{C}$ and nitrogen isotopes. These isotopes shall be produced by neutroninduced reactions. Neutrons will be produced by deuteron break-up, stripping or (d,xn) evaporation in a first target called neutron converter. The targets we envisage could be placed instead of the UCx target behind the converter. The $1500^{\circ} \mathrm{C}$-oven developed for SPIRAL-2 ${ }^{3}$ would be used to favor the release of reaction products. In the presently adopted scheme, based on fully stopping $40 \mathrm{MeV}$ deuterons in carbon, the spectrum of neutrons impinging on such a target has an energy-integrated conversion factor close to $1 \%$ of the primary beam intensity and has the following distribution: $50 \%$ of them are below $10 \mathrm{MeV}, 40 \%$ between 10 and $20 \mathrm{MeV}$, and $10 \%$ between 20 and $40 \mathrm{MeV}$. More details can be found in Ref. ${ }^{21}$.

\section{${ }^{6}$ He production}

The reaction selected to produce ${ }^{6} \mathrm{He}(0.8 \mathrm{~s})$ is ${ }^{9} \mathrm{Be}(\mathrm{n}, \alpha)$. T. Hirsh et al. ${ }^{22}$ from the Weizmann institute performed series of simulations using the Monte-Carlo MCNP4b code. An in-target production of $2.10^{13}$ pps is expected at SARAF using a $2 \mathrm{~mA}, 40$ $\mathrm{MeV}$ deuteron beam in truly optimal conditions (Li converter for neutron production, natural density $\mathrm{BeO}$, without spacing in the volume target). The strong ${ }^{9} \mathrm{Be}(\mathrm{n}, 2 \mathrm{n})^{7} \mathrm{Be}$ reaction doubles the number of useful neutrons ${ }^{22}$.

At the beginning stage at least, the SPIRAL-2 converter will be a rotating $C$ wheel. This lowers the neutron flux by a factor of 2 with respect to the Li-converter ${ }^{23}$. The $\mathrm{BeO}$ material will have $70 \%$ of natural density due to the porous $\mu$ m-structure necessary for He release. Moreover, the available space shall be filled to about 2/3 due to the crumbly nature of the pellets. Thus the apparent density will rather be between $33 \%$ and $50 \%$ of the natural one. Lower density reduces the neutron flux enhancement via ${ }^{9} \mathrm{Be}(\mathrm{n}, 2 \mathrm{n}){ }^{7} \mathrm{Be}$ down to 1.2 (if $\rho / 3$ ) to 1.4 (if $\rho / 2$ ). An in-target ${ }^{6} \mathrm{He}$ rate of $4.10^{11} \mathrm{pps}$ can be obtained from the convolution of the known experimental cross-section ${ }^{24}$ with 
the measured neutron distribution ${ }^{21}$, and assuming an effective density of $\rho / 3$ and 1 $\mathrm{mA}$ deuteron current at the beginning of operation of SPIRAL-2. However this calculation has not taken into account the channels $(n, t+p),\left(n,{ }^{3} H e+n\right),(n, d+d)$, (n,2p2n) which are opened above $20 \mathrm{MeV}$ but whose cross-sections are not known experimentally. This rate, while much lower than the yield calculated for SARAF, is still 50 times the one at SPIRAL- $1\left(8 \times 10^{9} \mathrm{pps}\right.$ at $\left.2.5 \mathrm{~kW}\right)$. Let us then further remark the extracted rate at SPIRAL1 of $2 \times 10^{8}$ pps without acceleration and $3 \times 10^{7}$ pps to $5 \times 10^{6}$ pps after acceleration depending on final ${ }^{6} \mathrm{He}$ energy.

Figure $5 \mathrm{a}$ shows the phase diagram of $\mathrm{BeO}$ calculated at GANIL with $\mathrm{F}^{*} \mathrm{~A}{ }^{*} \mathrm{C} * \mathrm{~T}$ code ${ }^{25}$ when the target is alone or when it is in contact with C, Ta, Mo, W or Re. Only $\mathrm{W}$ or Re do not reduce in the pressure-temperature range where $\mathrm{BeO}$ is in solid phase. Moreover at low pressure, the allowed temperature decreases. Off-line thermal tests of material at CERN-ISOLDE have shown that Re is the best choice (fig 5b). A collaboration ${ }^{26}$ (ISOLDE, GANIL, SOREQ) has recently performed an on-line experiment using neutrons on a $100 \mathrm{~g} \mathrm{BeO}$ target to produce ${ }^{6} \mathrm{He}$. A rhenium foil separated the $\mathrm{BeO}$ from the tantalum container. The ${ }^{6} \mathrm{He}$ production was comparable with the one at low energy at SPIRAL-1. The analysis of release efficiency is in progress.
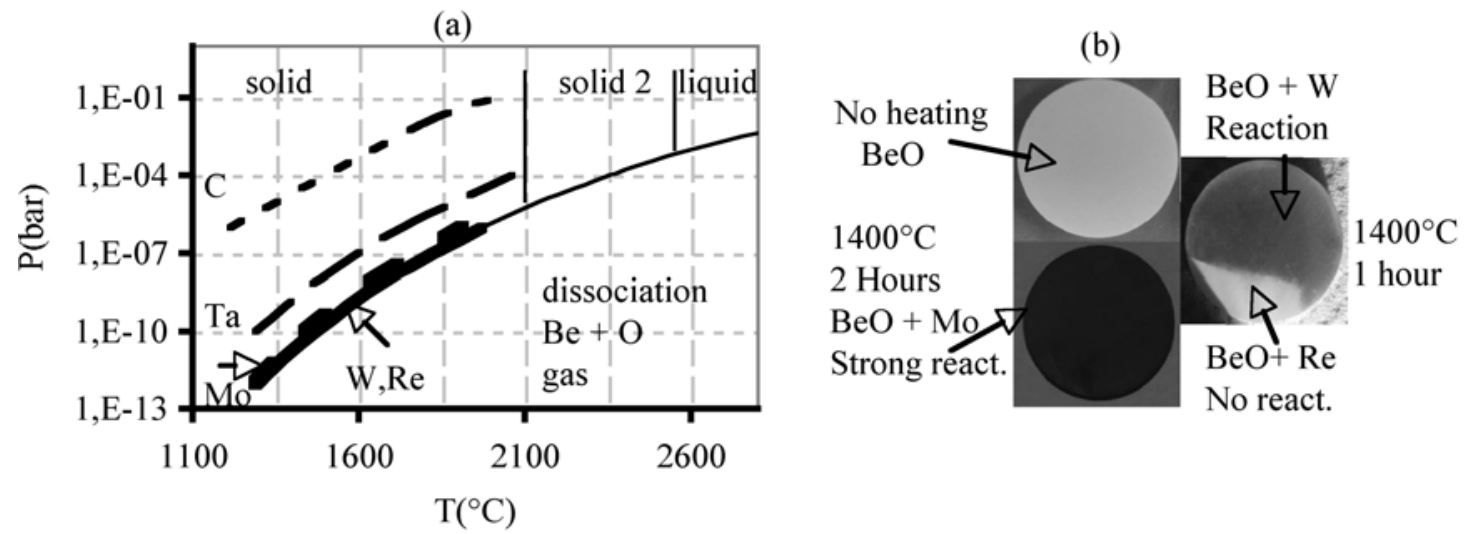

FIGURE 5 : (a) Phase diagram of $\mathrm{BeO}$ calculated with $\mathrm{F}^{*} \mathrm{~A}{ }^{*} \mathrm{C} * \mathrm{~T}$ code when alone (thin line) or in contact with $\mathrm{C}, \mathrm{Ta}, \mathrm{Mo}, \mathrm{W}$ or Re. $\mathrm{W}$ or Re do not reduce the pressure-temperature range of $\mathrm{BeO}$ in solid phase. (b) Off-line thermal test at Isolde : $\mathrm{BeO}$ alone at room teperature, in contact with $\mathrm{Mo}, \mathrm{W}$ and Re inserted in Ta boat at $1400^{\circ} \mathrm{C}$.

\section{${ }^{8} \mathrm{Li}$ production}

As for ${ }^{6} \mathrm{He}$, extensive simulations ${ }^{15,22}$ have been performed by the SOREQ group concerning ${ }^{8} \mathrm{Li}$ production by ${ }^{10} \mathrm{~B}(\mathrm{n}, \alpha){ }^{8} \mathrm{Li}$. In-target rate of $8.10^{12}$ pps is expected at SARAF assuming $2 \mathrm{~mA}$ deuterons, Li converter, and natural $\mathrm{B}$ target density. The yield at SPIRAL-2 is expected to be $1.410^{11}$ pps using $1 \mathrm{~mA}$ deuterons, C converter, and a BN target, which corresponds to 20 times the in-target SPIRAL-1 yields (7 $10^{9}$ pps at $1.5 \mathrm{~kW})$. However, $\mathrm{Li}$ is the most difficult alkali to be ionized. The ${ }^{8} \mathrm{Li}^{+}$ efficiency as measured on the SIRA test bench separator is only $510^{-5}$ pps. Off-line thermal tests are in progress at SOREQ with a recently acquired BN material with $\mu \mathrm{m}$ - 
structure. Material choice and diffusion measurement will be especially important since the ${ }^{8} \mathrm{Li}$ half-life is $0.8 \mathrm{~s}$ only. We note that stable $\mathrm{Li}$ has been released from $\mathrm{BN}$ with a short component of a few seconds ${ }^{27}$. $\mathrm{B}_{4} \mathrm{C}$ material will be also investigated.

\section{${ }^{15} \mathrm{C}$ and ${ }^{16,17,18} \mathrm{~N}$ production}

In general, neutron-rich nuclei could be produced by neutrons using various targets placed behind the converter. For instance, ${ }^{15} \mathrm{C},{ }^{16,17,18} \mathrm{~N}$ rates have been calculated using MCNP code at GANIL. The target is $\mathrm{Al}_{2} \mathrm{O}_{3} \quad\left(\rho=\rho_{\text {natural }} / 3\right)$. Figure 6 presents the expected yields calculated using cross-sections from MCNP, Pace4, or the simulation database EAF05. The available neutron energies are well overlapping with crosssections for (n, $\alpha$ ) channels, but ${ }^{18} \mathrm{O}(\mathrm{n}, \alpha){ }^{15} \mathrm{C}$ is not suitable as a big target due to the small natural abundance of ${ }^{18} \mathrm{O}(<0.2 \%)$. The neutron spectrum is too low in energy for efficient use of ${ }^{16} \mathrm{O}(\mathrm{n}, 2 \mathrm{p}){ }^{15} \mathrm{C}$. Alternatively, ${ }^{3} \mathrm{He}$ up to $72.5 \mathrm{MeV}$ should be available at the Linac. Higher-energy neutrons could be therefore produced by $\mathrm{C}\left({ }^{3} \mathrm{He}, \mathrm{xn}\right)^{28}$. Unfortunately, the neutron yields (in the 20-40 MeV range needed for $(\mathrm{n}, 2 \mathrm{p}))$ are of the same order as with $40 \mathrm{MeV}$ deuterons on carbon. Charged-particle reactions leading to ${ }^{15} \mathrm{C}$ are $\mathrm{B}^{15} \mathrm{~N}(\mathrm{~d}, 2 \mathrm{p})$ or $\mathrm{B}^{14} \mathrm{~N}(\mathrm{t}, 2 \mathrm{p})$. The former, due to low ${ }^{15} \mathrm{~N}$ natural abundance, leads to $7.10^{7}$ pps in the target. The cross-section of the second one is not known and it is in any case delicate to use a high-intensity tritium beam.

At SPIRAL-1 ${ }^{15,16} \mathrm{C}$ are easily produced in the target using ${ }^{18} \mathrm{O}$ projectile fragmentation. However, they cannot be released without evaporating the graphite target. This calls for another target than graphite. A metal oxide target allows release of ${ }^{15,16} \mathrm{CO}$ molecules. A first test at SIRA-GANIL ${ }^{29}$ has demonstrated the ${ }^{11,15,16} \mathrm{C}$ extraction using only $100 \mathrm{nAe}, 25 \mathrm{MeV} / \mathrm{A}^{22} \mathrm{Ne}$ beam and $\mathrm{Al}_{2} \mathrm{O}_{3}, \mathrm{HfO}_{2}, \mathrm{ZrO}_{2}$ targets. However, metal oxides in normal conditions of temperature and pressure are insulators. The stopped ${ }^{18} \mathrm{O}^{\mathrm{N}+}$ ions shall charge the target, possibly leading to discharge and consequent physical damage of the target. Noting that ${ }^{15,16} \mathrm{C}$ fragments have a higher range than the oxygen ions beam, a target in two parts could be a solution. The first part in graphite for radioactive production should be thick enough to stop the ${ }^{18} \mathrm{O}$ beam, but not the lighter- $\mathrm{Z}$ products. The second part in metal oxide acts as a catcher for lighter products and enables ${ }^{15,16} \mathrm{C}^{\text {stable }} \mathrm{O}$ molecule formation. This solution is rather complicated (separation of $\mathrm{C}$ and oxide parts by a window, need for an oven to heat the oxide, incomplete separation per range, etc).

Fragmentation of ${ }^{18} \mathrm{O},{ }^{22} \mathrm{Ne}$ or ${ }^{26} \mathrm{Mg}$ projectiles could be used for ${ }^{16,17,18,19} \mathrm{~N}$ production. The in-target yields calculated with the EPAX parameterization is from $10^{10}$ pps for ${ }^{16} \mathrm{~N}$ down to to $3.10^{7}$ pps for ${ }^{19} \mathrm{~N}$. An accelerated ${ }^{13} \mathrm{~N}(9.9 \mathrm{~m})$ beam is already available at SPIRAL-1 using a standard NANOGAN N+ ECR ion source with a cold transfer pipe. The measured efficiencies are: $7 \times 10^{-3}$ for ${ }^{13} \mathrm{~N}^{1+}, 5 \times 10^{-4}$ for ${ }^{13} \mathrm{~N}^{2+}$ and $\mathrm{C}^{13} \mathrm{~N}^{1+}$. $\mathrm{CN}$ molecule formation helps probably the $\mathrm{N}$ release from graphite $\mu \mathrm{m}$ structure.

The cold transfer pipe between target and ECR is probably a handicap for best efficiency for such short-lived isotopes ${ }^{16} \mathrm{~N}(7 \mathrm{~s}),{ }^{17} \mathrm{~N}(4.2 \mathrm{~s}),{ }^{18} \mathrm{~N}(0.6 \mathrm{~s})$ and ${ }^{19} \mathrm{~N}(0.3 \mathrm{~s})$ and molecule stability. A $1+$ ion source without cold pipe could be a better solution ${ }^{11}$. 


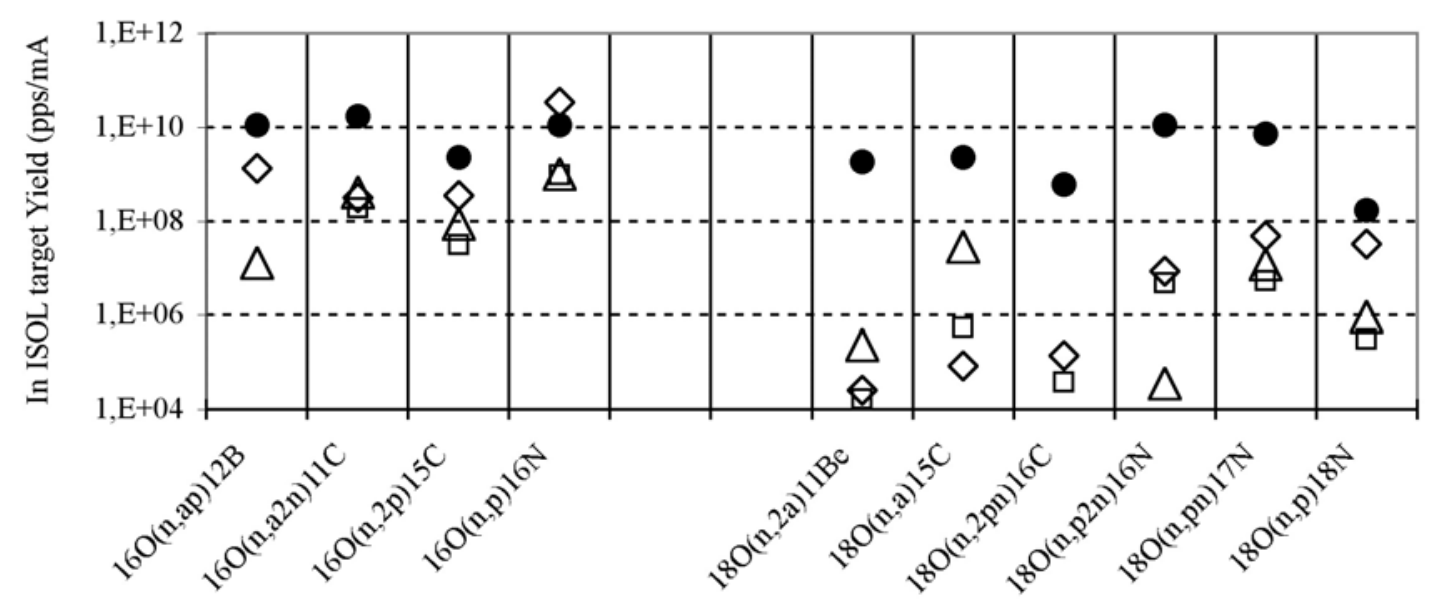

FIGURE 6 Expected yields (pps/1 mAp of deuteron beam on carbon converter) calculated using MCNP (diamonds) or cross-sections from PACE4 code (triangles) and simulation database EAF05 (squares). Yields inside SPIRAL-1 C target are also calculated (filled circle) using the code EPAX $^{14}$ and assuming $1.5 \mathrm{~kW}$.

\section{CONCLUSION}

The in-target yields at SPIRAL-2 for light-charged particles $\mathrm{p}, \mathrm{d}$, and ${ }^{3-4} \mathrm{He}$, and neutrons impinging on low-mass element targets have been estimated and compared with existing or potentially reachable values at SPIRAL-1.

For neutron-deficient nuclei a gain of yield in the targets of about a factor 10 is expected assuming that the SPIRAL-2 target could withstand $100 \mu \mathrm{A}$ of light-charged particles. Thermal behavior and reaction product release remain challenges to be solved. The targets $\mathrm{MgO}, \mathrm{Al}_{2} \mathrm{O}_{3}, \mathrm{SiC}$ are already used at ISOL installations but not at such high power. The first thermal studies and simulations performed at CENBG and GANIL for $\mathrm{C}\left({ }^{3} \mathrm{He}, \mathrm{n}\right){ }^{14} \mathrm{O}$ shows that $200 \mu \mathrm{A}$ of $1 \mathrm{MeV}$ protons can be accepted by a Cfoil target and shows the importance of defocusing and flatness of the primary beam profile.

For neutron-rich nuclei, a gain of about a factor 100 is expected for ${ }^{6} \mathrm{He},{ }^{8} \mathrm{Li}$ when a $5 \mathrm{~mA}$ deuteron beam will be available. SPIRAL-1 should be competitive for the nuclei ${ }^{15,16} \mathrm{C},{ }^{16,17,18} \mathrm{~N}$ and ${ }^{25} \mathrm{Ne}$. At SPIRAL2, an in-target gain of factor 10 is expected for ${ }^{23} \mathrm{Ne}$, ${ }^{25,26} \mathrm{Na}$ using $1 \mathrm{~mA}$ deuteron apart from any consideration of losses due to release. Experimental cross-sections for energetic neutron reactions, especially above $20 \mathrm{MeV}$, are scarce and often in disagreement with each other. It is further to be noted that neutron targets are very thick, making prompt release an even more harder-tosolve challenge than for n-deficient nuclei.

Finally, high charge states are required for post-acceleration in the CIME cyclotron; the $1+/ \mathrm{N}+$ breeding efficiency for such light nuclei is another challenge. 


\section{ACKNOWLEDGMENTS}

This work has been supported by the European Community FP7 - Capacities SPIRAL2 Preparatory Phase $N^{\circ} 212692$ and by the Région Basse Normandie for a $\mathrm{PhD}$ thesis (A.P.).

\section{REFERENCES}

1. WB_SP2_Final.pdf report. http://pro.ganil-spiral2.eu/spiral2/what-is-spiral2/physics-case/view

2. M.-G. Saint-Laurent, "Future opportunities with SPIRAL2 at GANIL "

Eighth International Topical Meeting on Nuclear Applications and Utilization of Accelerators (ACCAPP'07), Pocatello, Idaho (USA), 29/07/2007 - 08/08/2007. Eds. American Nuclear Society, Proc. (0) 268 and references therein

3. H. Frånberg et al., this conference

4. SPIRAL2 Preparatory Phase (SPIRAL2 PP): http://pro.ganil-spiral2.eu/spiral2/spiral2-pp-docs

5. P. Bertrand (private communication).

6. http://pro.ganil-spiral2.eu/users-guide/accelerators/spiral-beams

7. P. Jardin et al. "Latest results obtained at GANIL with new target-source systems dedicated to radioactive ion production" Review of Scientific Instruments 75(5) 1617-1620 Part2 May 2004

8. C. Eléon at al. "Development of a surface ionization source for the production of radioactive alkali ion beams in SPIRAL" Nucl. Inst. And Meth. In Phys. Res. B 266(2008) 4362-4367

9. P. Delahaye et al., this conference.

10. http://isolde.web.cern.ch/ISOLDE/

11. http://www.triumf.info/facility/research fac/yield.php

12. The European Activation System: Easy-2007 overview, R.A. Forrest, UKAEA FUS 533, EURATOM/UKAEA fusion association.

13. Code PACE4 included in LISE program http://groups.nscl.msu.edu/lise/lise.html

14. K. Summerer et al., Phys. ReV. C61 (2000)034607

15. M. Hass et al. "Light radio-isotopes for nuclear astrophysics and neutrino physics" J. Phys. G. Nucl. Part. Phys. 35 (2008) 014042 (6pp)

16. M. Loiselet et al; (private communication)

17. J. Singh, Nucl. Phys. A155(1970) 443-452

18. T. Nozaki and M. Iwamoto, "Yield of $14 \mathrm{O}$ for the reactions $14 \mathrm{~N}(p, n) 14 \mathrm{O}, 12 \mathrm{C}(3 \mathrm{He}, n) 14 \mathrm{O}$ and 12C(a,2n)14O" Radiochimica Acta 29,57-59(1981)

19. J. Mrazek, private communication

20. Comsol Multiphysics, version 3.5 htpp://www.comsol.com

21. G. Lhersonneau et al. "Neutron yield from carbon, light-and heavy-water thick targets irradiated by 40MeV deuterons" Nuclear Instruments and Methods in Physics Research Section A 603 (2009) 228-235

22. T. Y. Hirsh et al., "High Yield Production of 6He and 8Li RIB forAstrophysics and Neutrino Physics" $10^{\text {th }}$ International Workshop on Neutrino factories, Super beams and Beta beams June30July 52008

23. M. Hagiwara et al. J. Nucl. Sci. Tech.,41, issue.4,p. 399 (2004)

24. http://www.nndc.bnl.gov/exfor/exfor00.htm

25. Code $\mathrm{F}^{*} \mathrm{~A}^{*} \mathrm{C} * \mathrm{~T}$ http://www.crct.polymtl.ca/fact/index.php

26. T. Stora et al. to be published

27. S. Ichikawa et al. NIM B204 (2003) 372

28. K. Shin et al. Phys. Rev C29 (1994)1307

29. H. Frånberg "Production of exotic, short lived carbon isotopes in ISOL-type facilities" CERNTHESIS-2008-084. Berne Univ., 2008. 27 Oct 2008 